This is a copy of an article published in the Journal of Alternative \& Complementary Medicine () 2010 Copyright Mary Ann Liebert, Inc.; Journal of Alternative \& Complementary Medicine is available online at: http://online.liebertpub.com

Full Citation: Bishop FL, Yardley L, Lewith GT. (2010) Why consumers maintain complementary and alternative medicine use: A qualitative study. Journal of Complementary and Alternative Medicine, 16(2), 175-82. doi: 10.1089/acm.2009.0292

\title{
Why Consumers Maintain Complementary and Alternative Medicine Use: A Qualitative Study
}

Running Head: Why consumers maintain CAM use.

Authors: Felicity L Bishop $\mathrm{PhD}^{1 *}$, Lucy Yardley $\mathrm{PhD}^{2}$, George T Lewith $\mathrm{MD}^{1}$

${ }^{1}$ School of Medicine, University of Southampton, UK

${ }^{2}$ School of Psychology, University of Southampton, UK

*Corresponding author and contact for reprints - Dr Felicity L Bishop. Address:

Complementary Medicine Research Unit, Department of Primary Medical Care, School of Medicine, Aldermoor Health Centre, Aldermoor Close, Southampton, SO16 5ST.

Email: F.L.Bishop@southampton.ac.uk. Phone: +44 (0)2380 241072.

Word Count (main text excluding quotes): 4169

Word count (main text including quotes): 5240

Abstract word count: 243

Keywords: complementary therapies; medication adherence; qualitative research; CAM use; health knowledge, attitudes, practice. 


\section{$\underline{\text { Abstract }}$}

Objectives: Although research evidence exists to suggest why consumers use CAM, there remains a need to distinguish between factors and processes involved in the initial uptake of therapies and those involved in their subsequent maintenance. We therefore conducted a qualitative study to explore and describe consumers' reasons for maintaining or stopping CAM use.

Methods: This was a qualitative study. We interviewed 46 CAM consumers and 9 CAM practitioners, in two high-street CAM clinics in the UK. The interviews were analysed thematically using techniques from grounded theory.

Results: Consumers described and evaluated their CAM experiences along four dimensions: interpersonal (e.g. interactions with practitioners), physical (e.g. sensations such as touch or pain during treatment), affective (e.g. empowerment) and cognitive (e.g. beliefs about treatment). They evaluated their experiences in relation to their individual needs and expectations; financial considerations could limit maintenance of CAM use. Practitioners emphasised the effectiveness of treatment and themselves as contributing to consumers maintaining treatment, and recognised the role of financial considerations in decisions to stop CAM use.

Conclusions: This study suggests that experiences of conventional medicine are of limited importance after the decision to initiate CAM. Experiences of CAM were 
foremost in our consumers' decisions to maintain or stop specific CAM therapies.

Maintenance of CAM could occur even if consumers' experiences were not entirely positive. Our findings provide novel, systematic, insights that will be of particular interest to practitioners who want to support consumers as they decide whether to maintain CAM use. 
Complementary and alternative medicine (CAM) includes a range of diverse therapies that are not commonly available through conventional medicine outlets nor commonly taught in conventional medical schools, ${ }^{1}$ and epidemiological surveys suggest that CAM use is common amongst the general population..$^{2-9}$ Large-scale surveys provide a picture of the socio-demographic and clinical characteristics of CAM users, and the typical person who uses CAM is a well-educated woman of middle-age. ${ }^{3 ; 5-7 ; 10-13}$ CAM is used in relation to both general well-being and a range of specific, often chronic, illnesses. ${ }^{5 ; 14-19}$ Our understanding of why people use CAM rests on a growing number of predominantly small scale studies which have investigated the health beliefs and other psychological characteristics of CAM users (often compared to non-users) and the reasons that they themselves give for using CAM. These studies support the suggestion that people are both attracted to CAM and deterred by conventional medicine. ${ }^{20}$ Pull factors that encourage people to use CAM include a holistic orientation to health, illness, and treatment; ${ }^{14 ; 21-24}$ a desire to take an active role in treatment and/or develop an ongoing relationship with a caring practitioner; ${ }^{25-27}$ a desire to experience 'natural' therapies which are believed to have few if any adverse side-effects. ${ }^{25 ; 28-30}$ People who use CAM may also hold less conventional philosophies in general ${ }^{14 ; 31 ; 32}$ and may be more likely to have certain personality characteristics, such as openness to experience. ${ }^{33 ; 34}$ Push factors that deter people from using conventional medicine and thus contribute to CAM use include: dissatisfaction with the quality of the doctor-patient relationship; ${ }^{23 ; 35 ; 36}$ experiencing (or belief that one will experience) adverse side-effects from conventional medicine $;{ }^{37-39}$ dissatisfaction with a lack of perceived or potential efficacy of conventional interventions. ${ }^{22 ; 27 ; 40}$ 
In an early review of the literature on CAM use, Siahpush highlighted the need to distinguish between factors that might be associated with the initiation of CAM use and those that might be more relevant to understanding its maintenance. ${ }^{41}$ A few crosssectional quantitative studies suggest differences between new and established CAM users, ${ }^{42 ; 43}$ those with high and low commitment to CAM,, $4 ; 4$ and between those who rely on CAM and those who use it alongside conventional medicine. ${ }^{14}$ Adherence to CAM might be associated with patients' experiences of a therapy, ${ }^{46}$ and their perceptions of their practitioner ${ }^{47}$ and illness. ${ }^{48}$ Men with prostate cancer were more likely to stop using CAM when a high degree of effort was required to maintain use. ${ }^{49}$ In qualitative studies, people who use CAM report benefiting from and highly valuing the relationship with their practitioner. ${ }^{50-55}$ Some qualitative work also suggests that the benefits experienced from CAM can encourage further CAM use, while the financial cost of CAM and a perceived lack of effectiveness can limit it. ${ }^{51 ; 56-60}$ Yardley and colleagues ${ }^{61}$ showed how patients' perceptions of chiropractic are shaped through dynamic interactions between concrete experiences (of symptomatic relief and commentary from their practitioner) and abstract beliefs (about treatment and illness). Finally, models of CAM use in cancer illustrate the iterative and dynamic nature of CAM decision-making, and show how patients' decisions to start, continue, and stop using CAM are closely entwined with the cancer trajectory. ${ }^{62-66}$ In summary, factors that might be involved in the maintenance of CAM use have been identified, but few of these studies have focused exclusively on consumers' decisions to maintain or stop CAM use, and so this is an area that requires further study across different settings. Such work is important not only to further our conceptual understandings of CAM use but also to provide systematic, evidence-based 
knowledge to inform those individuals (e.g. CAM practitioners and providers) who might support consumers as they make decisions about using CAM.

In the UK, CAM is used predominantly in the private sector, ${ }^{5}$ and CAM clinics are now commonly seen in town and city centre high streets and shopping centres. Such visible and comparatively accessible clinics (in terms of cost and location) might represent an important aspect of the future of CAM provision, potentially widening access to CAM amongst the community and placing it firmly in a consumerist setting. It thus constitutes a valid and indeed valuable setting for research into CAM use behaviours. In this study we refer to people who use CAM as 'consumers', and this reflects the setting for our research. The aim of our study was to explore why CAM consumers decide to maintain or stop CAM use.

\section{Methods}

\section{$\underline{\text { Setting }}$}

Field work was conducted in two high-street CAM clinics (in southern England), which had been established for approximately 18 months and were run by and located within the premises of a high street company primarily known for being a pharmacy, which also retails a range of other products, including beauty and personal hygiene products. The clinics offered a range of therapies: aromatherapy massage, herbalism, homeopathy, osteopathy and reflexology. The company that owned the clinics co-funded this study, but had no role in its methodological design or analysis, or the decision to publish this paper. The decision to conduct the study in these clinics emerged from negotiations 
with the funders and an agreement to develop knowledge that would be directly relevant to the company. The clinics provided a valuable context because a) they were highly accessible and visible to people who might not otherwise have considered CAM use they thus represented an arena which had the potential to widen access to CAM and to bring it into a consumerist setting, and b) they offered a range of CAM therapies allowing us the potential to generate findings that applied to more than one therapeutic modality.

\section{Ethical Issues}

Ethical approval was granted by the School of Psychology, University of Southampton, Ethics Committee. Ethical issues can be complex when field work is undertaken for a prolonged period of time and the researcher becomes a trusted and accepted member of a setting. Before commencing fieldwork the researcher met with all practitioners to discuss the project and to seek informed consent. Her identity in the setting was as a student interested in complementary medicines, and she reinforced her identity as an independent researcher by wearing a University identity card and not wearing the clinic uniform.

\section{Data Generation and Collection}

The researcher spent a period of three months in the two clinics, attending the clinics on week days and week-ends to gain access to the range of people attending for different therapies. This ethnographic field-work included the collection of different forms of data (e.g. documents, photographs) in order to allow a rich multi-faceted account of CAM use to be developed and to enable more focused research questions to emerge, such as the one addressed here. The present analysis focuses on the interview data as this is most 
relevant to understanding, from consumers' perspectives, why CAM consumers decide to maintain or stop CAM use. Consistent with the ethnographic approach to the field-work, interviews were conducted in a range of styles including semi-structured, informal, and unstructured. Consumers were invited to take part in an interview by either their practitioner or the researcher, who approached them either before or after their appointment. Decisions about who to interview were guided by the principal of maximum variation sampling. Attempts were made to interview, for example, consumers using different therapies (because we anticipated that people attending different therapies might emphasise different aspects of experience, all of which needed to be incorporated into any comprehensive model) and consumers who were new or returning for follow-up appointments were interviewed (because 'new' consumers would be well-placed to tell us about early decisions to maintain or stop CAM while those who were returning for follow-ups would be able to tell use both about the consequences of such early decisions and any subsequent decisions and experiences). Interviews were carried out with 46 consumers (42 women and 4 men) and 9 practitioners. The consumers were attending the clinics for aromatherapy massage (12 people), herbalism ( 3 people), homeopathy ( 8 people), osteopathy (13 people), or reflexology (12 people). Twenty five interviews were carried out after a consumer's initial appointment for a therapy, and twenty three interviews were carried out after follow-up appointments. Five people were interviewed twice in order to provide some insights into individuals' journeys as they went from 'new' to 'returning' visitors to the clinics. These interviews thus provided a longitudinal perspective that acted as a check on our otherwise 'snapshot' approach. Audio-tapes and notes were used to record interviews wherever possible; if participants did not want to 
be recorded notes were made during and immediately after interviews. Consumers were invited to take part in interviews either by their practitioner or by the researcher. All participants were allocated, or chose their own, pseudonyms to protect their anonymity.

\section{Data Analysis}

Audiotapes were transcribed verbatim (and transcriptions reviewed for accuracy) and field notes were typed up both during and immediately following the field-work. Atlas.ti was used to facilitate data organisation, management and analysis. The analysis began during the field work, when initial impressions of both potential themes and the direction of the research were noted. Following the field work and a period of data immersion, the textual data were first analysed using inductive, open coding including in vivo codes. At this stage each line of every text was annotated with a code. Similar codes were then merged to develop categories, which were refined by comparing different categories with each other and comparing different instances of the same categories (both across and within participants). This analytic method, the constant comparative technique, was drawn from Strauss and Corbin's version of grounded theory. ${ }^{67}$ As the analysis progressed other techniques were also employed, including axial coding (where coding focuses on a smaller number of higher level categories, seeking to detail their characteristics) and deviant case analysis (where attempts are made to seek out instances in the data that are inconsistent with the emerging analysis). In the final stages of analysis the aim was to develop process-oriented themes that answered the analytic question 'what is happening here'. Three main process-oriented themes were developed which could explain the bulk of the data and provide insights into consumers' 
behaviour. These themes were labelled Finding a Therapy, Finding a Practitioner, and Experiencing and Evaluating CAM. This paper reports on the latter theme, Experiencing and Evaluating CAM, and considers both practitioners' and consumers' experiences. In relation to consumers, the findings are organised around the three main consequences of experiencing and evaluating CAM: maintaining CAM use, returning to CAM, and stopping CAM use. Quotations have been selected to present typical illustrations of participants' talk. A separate analysis of this data focussed on how patients conceptualise CAM therapies and has been reported previously ${ }^{68}$.

\section{Findings}

\section{CAM Practitioners}

Practitioners' talk about why they thought people came back to see them was characterised by two themes - the impact of the treatment itself on their patients and the practitioners themselves as important factors in the maintenance of CAM use. For example, Sally said that her patients come back because 'the treatment's working and they can see that. Hopefully me.' In comparison why people stop CAM use was more mysterious for the practitioners. John said that: 'People don't turn up for the follow up and then pop up again six months or even years later, saying that you helped them before and they've got a new problem.' Practitioners felt that financial cost could prevent the maintenance of CAM use, but they perceived that they had no say in the amount of money charged for their therapy in the clinic and so felt as if they had little control over the business side of CAM provision. 
Paula: If it was vouchers or a present or they can't really afford it that's probably the last time I see them until their next birthday. And the people like old aged pensioners they're not getting paid so it's quite a lot of money for them and very often they would love to come back [...] that's a bit frustrating [...] there's nothing that I can do about it.

\section{$\underline{\text { CAM Consumers }}$}

Four sub-themes were identified that reflected the main dimensions of consumers' experiences of treatment. The interpersonal dimension of experience reflects the relationship that consumers had with their practitioner and the communication that occurred between them. The physical dimension of experience comprises the sensations that consumers experienced during treatment or thought resulted from treatment, such as touch or pain. The affective dimension incorporates the more emotional aspects of treatment experiences, such as feeling empowered, happy or re-assured. Finally the cognitive dimension reflects aspects of the treatment experience that occur on a more abstract level (e.g. attitudes, beliefs) and can also include changes in cognitions that result from treatment (e.g. gaining new knowledge about a treatment). In describing these different dimensions of experience, CAM consumers also evaluated their experiences in relation to their individual needs and expectations (see Box). Practical considerations also featured in consumers' talk about maintaining and stopping CAM use.

\section{CAM Consumers: Maintaining CAM use.}


CAM consumers who had been seeing their practitioner for more than six months evaluated their treatment positively. They provide clear examples of how the different dimensions of experience feed into decisions to maintain CAM use. Theresa had been seeing the homeopath for 18 months, and both the physical impact of homeopathy and her trust in the homeopath (Ian) appeared to contribute to her maintaining her CAM use: 'I was very impressed when I met Ian and realised he knew what he was talking about, and he's helped me no end.' Experiences did not have to be exclusively positive in order for CAM use to be maintained. The experience of taking her remedies had not always been pleasant, but Theresa continued to use them because she found them effective, and less unpleasant than the conventional equivalent.

Theresa: The drops for the blood pressure [...] they're absolutely disgusting but it's brought my blood pressure down so they say the nastiest medicines are best don't they [...] And better to have a disgusting flavour first thing in the morning than swollen legs and breathlessness and all that sort of thing [...] from the other medication

Kay had seen the homeopath twice, and talked about her extensive experience of also using osteopathy and chiropractic in the past. She summed up her ongoing use of CAM forms and the importance of previous experience when she said 'The proof was in the eating.' She went on to explain that the affective dimension of experiencing CAM treatments through the therapeutic relationship also plays an important role in maintaining her CAM use. 
Kay: It worked [chiropractic/osteopathy], I walked out and so you keep going. My experiences as a child with eczema [with homeopathy] I think had the biggest impact on my use of alternative health. Also, I feel more in control with alternative medicine that I do with a GP. I've only ever found one GP that does this shift in power or control. It really makes a difference - coming out feeling you're doing something positive.

Some CAM consumers who were interviewed had seen their practitioner only once and had little previous experience of CAM. The idea that it is too soon to pass judgement on whether a therapy 'works' was characteristic of such consumers. However, again these consumers described experiences across all four dimensions identified above. Betty was interviewed after her first ever reflexology appointment, which surpassed her expectations and had an immediate physical impact on her, as well as leading to a cognitive shift in her understanding of reflexology.

Betty: Well I didn't appreciate the treatment basis of it, not until I actually had it. I thought it would just be quite nice and relaxing. I was amazed at how it helped my feet, they feel so much better already. And I've got other problems as well, back pain, and I'm not sleeping very well at all [...] And she Lara [the reflexologist] can pick all that up through your feet. Lara was explaining it all to me. My feet feel wonderful now. They're quite painful most of the time, even sitting down, especially when I've been at work all day. I've got no pain now 
though, all I can say is wow!

Betty was asked whether she thought she would come back for another reflexology appointment, and despite her positive experience she did not commit herself to a judgement on reflexology: 'I'm still going to stay a bit sceptic though. I need more appointments and see what happens, then I'll know if it really is good.' When further prompted about what she would base this judgement on, Betty focused on the immediate and direct physical benefit to her feet that she has found from reflexology. By focusing on this, Betty could avoid taking on board the principles underlying reflexology, and she could talk of reflexology as a foot massage, retaining her scepticism regarding the theoretical framework of reflexology as a form of health care.

Betty: Well I think it is worth it just for my feet. The other stuff would be an extra benefit. I just think that if it can help with all the other things, then why don't doctors and hospitals use it?

Other participants also experienced some physical impact of their treatment and decided to come back and 'give it a chance'. This process could be shaped by their interpretation of what their practitioner had told them during their first consultation (i.e. the interpersonal dimension). Jasmina was interviewed when she came into the clinic to pick up a repeat prescription from the herbalist, having had one consultation and taken the prescribed herbal preparation for one month. Jasmina thought that the herbs had had some effect on her, but was unsure exactly what effect or how the herbs worked. 
Jasmina: It was quite strange when I first took it um I could feel things like a funny sensation in my stomach so I knew it was doing something [...] maybe it's mind over matter or something I don't know but it seems to have um helped my periods this time round.

Later on in the interview Jasmina said that 'it seems to have done something to me but um obviously it's too soon to know one way or another.' When asked how long she intended continue with herbalism, she drew on advice from the herbalist: 'Julie said it must be about three months before I can know so I think I'll give it 'til then.' Thus the physical and interpersonal dimensions of treatment appear to have contributed to Jasmina's evaluation and decision to maintain her use of herbalism. The herbalist provided a timeframe within which Jasmina could continue experiencing and evaluating her treatment. Such timeframes also provided consumers with a guide to likely financial cost of maintaining CAM use.

Linda: Yes, she said to come back in two weeks and see how it's going but that should be it

I: That's nice and quick

Linda: Yes, some people take you for a ride a bit keep you going for three months and it costs a fortune, so now I'm quite happy with Sally [osteopath] doing my neck today it's much gentler and I feel better now even [...]. It's very difficult to say at this stage if it's going to get better or not. After two sessions you can't 
really know what the outcome's going to be, but she seems pleased with what she's done and she does know what she's doing but I'll have to wait and see I: Ok and why did you come back today then Linda: Because at the start she said I would need more than one session and then she said she'd say today how many more I needed, and that most people don't need more than five, so I was happy to come back today give it a chance

\section{$\underline{\text { Returning to CAM }}$}

Returning to CAM emerged as a distinct form of maintaining CAM use, in which consumers returned for a new episode of treatment to a form of CAM they had used previously. CAM consumers who did this explained their current use of a therapy by talking about how it had successfully met their needs previously and how, based on their past experience and current problems, they expected it to meet their current needs. Consumers also reported returning to CAM because they experienced a specific physical problem, they wanted to improve their general wellbeing, or they believed that the particular CAM was consistent with their health beliefs. For example, Abby returned to osteopathy for a recurring back and neck problem.

Abby: Well because I've got neck and back trouble that I've had for quite some years anyway so I've been to osteopaths before [...] I think me I'm one of those people that I tend to adjust to things so if my neck hurt I stop doing whatever it was and you suddenly realise I've been putting up with this and this is ridiculous why don't I just go and get it sorted. 
Interestingly, past experience of a CAM did not have to be successful to encourage consumers to return. Kay constituted an extreme example of this in that she had previously tried homeopathy but it had made her symptoms worse and she felt unable to stick to the treatment because she was starting a new job at the time. This experience did not put her off using homeopathy and in the following quotation she talks explicitly about how she returned to homeopathy because she believed it was more appropriate (than conventional medicine) given the nature of her symptoms and her preference for holistic interventions.

Kay: This time, I've got more of a general feeling that my body is not functioning properly. You can't go to your GP for this. Also I'm conscious of the time pressure on GPs. They look for specific causes and it could be a whole series of things and it would take ages to find it. I believe in homeopathic. It's convenient and affordable and you get a good service at [clinic]. Also, when you have general malaise homeopathy is better, it is a general, holistic approach. I think as well with my family history, the problems my mother and father have had, I want to prevent similar problems. I can't go to my GP for that, but homeopathy takes it into account.

\section{CAM Consumers: Stopping CAM Use}

A number of participants reported treatment episodes at other clinics which they evaluated negatively and so did not continue. Again, all four dimensions of experience 
were apparent in decisions to stop CAM use, as were practical considerations. While Helen found some aspects of acupuncture positive, it did not meet her expectations and was expensive: 'It was relaxing and I enjoyed it but I didn't lose weight and it was too expensive really.' A combination of experiencing physical side-effects from a Chinese herbal remedy and feeling as if she was forced into her treatment by the practitioner led Clair to stop using Traditional Chinese Medicine (TCM).

Clair: I tried TCM once, but I got bad effects from the herbs and he refused to change them. [...] I did not go to the third one [appointment], even though I'd paid for it I didn't want to go. There's an issue of trust with TCM.

Some interviewees who evaluated their treatment at the clinic positively said that the financial cost would put a limit on their ongoing use. For example, Freya says that reflexology 'could be cheaper. I don't come very often.' However, few participants evaluated their treatment at the clinic in negative terms and said they were unlikely to use the treatment again. Those who did had been bought their appointments as gifts. While Max enjoyed his reflexology appointment and found it relaxing, he thought it was too expensive for him to use again.

Max: [laughs] I've just paid the bill not at forty five quid [laughter] so no I: Ok if it didn't cost so much Max: Oh sure for a nice foot massage I wouldn't be coming back cos I thought it was any good for me but it was very nice. 
CAM consumers also described stopping an episode of treatment because they considered it to have been successful. In these cases, participants were very positive about possible future use of the treatment. Robby thought his first ever experience of osteopathy was very successful, and on the basis of this success (and his view of osteopathy as more appropriate for back problems than seeing his GP) he would use osteopathy again.

Robby: Tim explained didn't get too technical, explained what he felt had happened. [...] It was a very thorough examination and his treatment really targeted the area [...] I certainly feel better. Whether that's psychosomatic or not I don't know but I feel more reassured if you like. [...] Tim or his colleagues would have to know the structures of the bone, how they interact, what is right, what is wrong within the body so that they can detect any potential errors. And in that sense $[\ldots]$ if I have a joint or back problem I would rather talk to say Tim because I feel his examination would be better than a GP who is more likely to talk to me about what is happening, prescribe some anti- inflammatory drugs and tell me to go away and if in two weeks time it's not any better come back and see me $[\ldots]$.

\section{Discussion}

The CAM consumers that we interviewed described maintaining their CAM use based on positive evaluations of (at least) one of four dimensions of treatment - physical, affective, 
cognitive and interpersonal. While positive evaluations were typical, it is important to note that CAM use could be maintained despite negative evaluations of some aspect of treatment (e.g. taste). The interpersonal dimension of treatment appeared to be particularly important early in treatment. According to CAM consumers, practitioners helped to encourage their maintenance of CAM use early in treatment by providing them with a timeframe within which they might expect to experience benefit(s). Our analysis suggests that the processes and factors involved in maintaining CAM use are slightly different to those involved in CAM use in general: maintaining CAM use appears to be more dependent on positive experiences of CAM (pull factors) than on negative experiences of conventional medicine (push factors). This is consistent with some previous research ${ }^{43 ; 47}$ (but not all ${ }^{51}$ ). Our interviewees described stopping CAM use, if either a) it had successfully resolved an acute problem, or b) it had failed to meet their expectations and/or provide desired health benefits, and/or they felt it was too expensive. The CAM practitioners who we interviewed also talked about how the physical effectiveness of CAM and their skills as practitioners can encourage maintenance, and the role of financial considerations in decisions to stop using CAM.

The field-work from which this analysis was derived was situated within one particular therapeutic setting and focussed on two clinics. This approach facilitated an indepth study of the initiation and maintenance of CAM use in this consumerist setting, but could leave the transferability of the findings to other settings questionable. In particular ongoing CAM use in a publicly funded setting (e.g. the NHS) might be quite different from ongoing CAM use in the private sector. The similar location of the two clinics also limits the extent to which we would want to transfer our findings for example to inner- 
city settings or CAM users in other countries. Furthermore, there are likely to be additional illness-specific factors that can be involved in the decision-making process that will not have been identified in this study of CAM use in a diverse group of people. This work may also be limited by a reliance on one-off interviews with participants (although five were interviewed twice and interviewees ranged from first-time CAM users to experienced, committed users). The role of the company in co-funding the research could have influenced the practitioners' disclosures during the interviews; to mitigate against this the interviewer emphasised the intellectual independence of herself and her research from the clinic and re-assured the practitioners that their interviews would not be made available to the company, and that any verbatim quotes used in publications would be anonymised.

Commonalities between our work and existing studies support the credibility of our findings and suggest that at least on an abstract level our findings might be transferable to other CAM treatments if not settings. Others have described the experience of CAM treatments as multidimensional, for example Luff and Thomas ${ }^{51}$ highlighted the physical and psychological dimensions. Yardley et al ${ }^{61}$ emphasised the importance of the interpersonal dimension in their discussion of chiropractors' online commentaries, which they explained might shape patients' perceptions of and adherence to their treatment through providing explanations linking treatment approach, illness perceptions, and likely outcomes. The role of financial considerations and perceived lack of benefit have previously been identified as contributing to stopping using CAM, and perceived benefits have previously been shown to encourage ongoing CAM use. ${ }^{51 ; 56-60}$ This study adds to the understanding of the processes involved in CAM use by 
specifying and describing the different dimensions of experience that patients consider when maintaining or stopping CAM, and by focusing on an emerging setting for CAM consumption - the high street clinic. Keeping in mind the caution required in terms of the transferability of the analysis (which should be tested in future work), the findings from this study have a number of implications for research and CAM provision. Peoples' experiences of treatments were analysed as belonging to four dimensions, physical, affective, cognitive and interpersonal. This is relevant to the question of what mechanisms underlie experiences of CAM, and suggests that researchers need to attend to a range of possible levels of experience and to develop sophisticated methodologies in order to do this. It also highlights a limitation in scope of existing quantitative work on CAM use. Questionnaire-based studies (including those by the authors) primarily assess peoples' interpersonal and, to an extent, physical experiences of therapy, but rarely evaluate their affective or cognitive experiences. This study highlights the broadness of CAM as an experience and the need to develop appropriate tools to quantitatively evaluate the whole range of dimensions of experiences of CAM. Both the close relationship between different dimensions of peoples' experiences and the shear range of experiences also has implications for research into CAM outcomes, providing further evidence that patient-centred outcome measures such as the MYMOP ${ }^{69}$ might be more appropriate than generic outcome measures that focus on a narrow range of primarily physical experiences. The finding that participants were often unwilling to commit themselves to an evaluation of treatment (citing the importance of trying something out or waiting to see what happens) also highlights that the timing of any self report measures related to appraisal of treatment requires further theorising and empirical study. In 
relation to practice, perhaps the most encouraging finding is that practitioners appear to have an important role to play in their patients' decisions about whether or not to continue with treatment. According to our sample of CAM consumers, providing a timeframe early in treatment can encourage them to postpone any premature judgements of effectiveness. Our findings might usefully inform CAM practitioners as they work both to support consumers in making decisions about CAM use and also to decrease barriers for those consumers who wish to maintain CAM use. However any specific recommendations for practice based on this single qualitative study would themselves be premature, and further research is needed to determine effective and ethical means to support consumers as they make decisions to maintain or stop CAM use. 


\section{Acknowledgements}

The authors would like to thank the consumers and practitioners who took part in this study and the staff at the clinics. Dr Bishop was supported by an ESRC CASE Studentship in collaboration with Boots plc. Professor Lewith's post is funded by a grant from the Rufford Maurice Laing Foundation and at the time this research was carried out he was a consultant to Boots plc.

\section{$\underline{\text { Disclosure Statement }}$}

No competing financial interests exist. 
Reference List

(1) Eisenberg DM, Kessler RC, Foster C, Norlock FE, Calkins DR, Delbanco TL. Unconventional medicine in the United States - Prevalence costs, and patterns of use. N Engl J Med 1993; 328(4):246-252.

(2) Molassiotis A, Fernandez-Ortega P, Pud D, Ozden G, Scott JA, Panteli V et al. Use of complementary and alternative medicine in cancer patients: a European survey. Annals of Oncology 2005; 16:655-663.

(3) Nilsson M, Trehn G, Asplund K. Use of complementary and alternative medicine remedies in Sweden. A population-based longitudinal study within the northern Sweden MONICA Project. J Intern Med 2001; 250(3):225-233.

(4) Tan M, Uzun O, Akcay F. Trends in complementary and alternative medicine in Eastern Turkey. J Altern Complement Med 2004; 10(5):861-865.

(5) Thomas KJ, Nicholl JP, Coleman P. Use and expenditure on complementary medicine in England: a population based survey. Complement Ther Med 2001; 9:2-11.

(6) Tindle HA, Davis RB, Phillips RS, Eisenberg DM. Trends in use of complementary and alternative medicine by US adults: 1997-2002. Altern Ther Health Med 2005; 11(1):42-49.

(7) MacLennan AH, Myers SP, Taylor AW. The continuing use of complementary and alternative medicine in South Australia: costs and beliefs in 2004. Med J Aust $2006 ; 184: 27-31$. 
(8) Lim MK, Sadarangani P, Chan HL, Heng JY. Complementary and alternative medicine use in multiracial Singapore. Complement Ther Med 2005; 13(1):16-24.

(9) Shmueli A, Shuval J. Use of complementary and alternative medicine in Israel: 2000 vs. 1993. Isr Med Assoc J 2004; 6(1):3-8.

(10) McFarland B, Bigelow D, Zani B, Newsom J, Kaplan M. Complementary and alternative medicine use in Canada and the United States. Am J Public Health 2002; 92(10):1616-1618.

(11) Bausell RB, Lee W-L, Berman BM. Demographic and health-related correlates of visits to complementary and alternative medical providers. Medical Care 2001; 39(2):190-196.

(12) Buono MD, Urciuoli O, Marietta P, Padoani W, Leo DD. Alternative medicine in a sample of 655 community-dwelling elderly. J Psychosom Res 2001; 50(3):147154.

(13) Bishop FL, Lewith GT. Who Uses CAM? A Narrative Review of Demographic Characteristics and Health Factors Associated with CAM Use. eCAM 2008; ePub ahead of print(doi:10.1093/ecam/nen023).

(14) Astin JA. Why patients use alternative medicine. Results of a national study. JAMA 1998; 279(19):1548-1553.

(15) Eisenberg DM, Davis RB, Ettner SL, Appel S, Wilkey S, Rompay M et al. Trends in alternative medicine use in the United States, 1990-1997. Results of a followup national survey. JAMA 1998; 280(18):1569-1575.

(16) Lee GBW, Charn TC, Chew ZH, Ng TP. Complementary and alternative medicine use in patients with chronic diseases in primary care is associated 
with perceived quality of care and cultural beliefs. Fam Pract 2004; 21(6):1-7.

(17) Gollschewski S, Anderson D, Skerman H, Lyons-Wall P. Associations between the use of complementary and alternative medications and demographic, health and lifestyle factors in mid-life Australian women. Climacteric 2005; 8(3):271278.

(18) Wolsko PM, Eisenberg DM, Davis RB, Ettner SL, Phillips RS. Insurance coverage, medical conditions, and visits to alternative medicine providers: Results of a national survey. Arch Intern Med 2002; 162(3):281-287.

(19) Nielsen MW, Hansen EH, Rasmussen NK. Use of Natural Medicines in the Danish Population: A National Cross-Sectional Survey. Ann Pharmacother 2005; 39:1534-1538.

(20) Vincent C, Furnham A. Why do patients turn to complementary medicine? An empirical study. Br J Clin Psychol 1996; 35:37-48.

(21) Furnham A, Forey J. The attitudes, behaviors and beliefs of patients of conventional vs. complementary (alternative) medicine. J Clin Psychol 1994; 50(3):458-469.

(22) Furnham A, Smith C. Choosing alternative medicine: A comparison of the beliefs of patients visiting a general practitioner and a homeopath. Soc Sci Med 1988; 26(7):685-689.

(23) Furnham A, Kirkaldy B. The health beliefs and behaviours of orthodox and complementary medicine clients. Br J Clin Psychol 1996; 35:49-61.

(24) Richardson J. What patients expect from complementary therapy: A qualitative study. Am J Public Health 2004; 94(6):1049-1053. 
(25) Bishop FL, Yardley L, Lewith G. Developing a measure of treatment beliefs: The complementary and alternative medicine beliefs inventory. Complement Ther Med 2005; 13:144-149.

(26) Hsiao A-F, Wong MD, Kanouse DE, Collins RL, Liu H, Andersen RM et al. Complementary and alternative medicine use and substitution for conventional therapy by HIV-infected patients. J Acquir Immune Defic Syndr 2003; 33:157165.

(27) Boon H, Stewart M, Kennard MA, Gray R, Sawka C, Brown JB et al. Use of Complementary/Alternative Medicine by Breast Cancer Survivors in Ontario: Prevalence and Perceptions. J Clin Oncol 2000; 18(13):2515-2521.

(28) O'Callaghan FV, Jordan N. Postmodern values, attitudes and the use of complementary medicine. Complement Ther Med 2003; 11(1):28-32.

(29) Cassileth BR, Lusk EJ, Strouse TB, Bodenheimer BJ. Contemporary unorthodox treatments in cancer medicine. Ann Intern Med 1984; 101:105-112.

(30) George J, Ioannides-Demos LL, Santamaria NM, Kong DCM, Stewart K. Use of complementary and alternative medicines by patients with chronic obstructive pulmonary disease. Med J Aust 2004; 181(5):248-251.

(31) Messerli-Rohrbach V. Personal values and medical preferences: postmaterialism, spirituality, and the use of complementary medicine. Forsch Komplementarmed Klass Naturheilkd 2000; 7:183-189.

(32) Furnham A, Beard R. Health, just world beliefs and coping style preferences in patients of complementary and orthodox medicine. Soc Sci Med 1995; 40(10):1425-1432. 
(33) Honda K, Jacobson JS. Use of complementary and alternative medicine among United States adults: the influences of personality, coping strategies, and social support. Prev Med 2005; 40(1):46-53.

(34) Furnham A. Are modern health worries, personality and attitudes to science associated with the use of complementary and alternative medicine? British Journal of Health Psychology 2007; 12:229-243.

(35) Bernstein JH, Shuval JT. Nonconventional medicine in Israel: consultation patterns of the Israeli population and attitudes of primary care physicians. Soc Sci Med 1997; 44(9):1341-1348.

(36) Moore AD, Petri MA, Manzi S, Isenberg DA, Gordon C, Senecal JL et al. The use of alternative medical therapies in patients with systemic lupus erythematosus. Arthritis and Rheumatism 2000; 43(6):1410-1418.

(37) Boon H, Westlake K, Stewart M, Gray R, Fleshner N, Gavin A et al. Use of complementary/alternative medicine by men diagnosed with prostate cancer: prevalence and characteristics. Urology 2003; 62(5):849-853.

(38) de Visser R, Ezzy D, Bartos M. Alternative or complementary? Nonallopathic therapies for HIV/AIDS. Altern Ther Health Med 2000; 6(5):44.

(39) Rawsthorne P, Shanahan F, Cronin N C, Anton P A, Lofberg R, Bohman L et al. An international survey of the use and attitudes regarding alternative medicine by patients with inflammatory bowel disease. The American Journal of Gastroenterology 1999; 94(5):1298-1303.

(40) Verhoef MJ, Sutherland LR, Brkich L. Use of alternative medicine by patients attending a gastroenterology clinic. Canadian Medical Association Journal 
$1990 ; 142(2): 121-125$.

(41) Siahpush M. A critical review of the sociology of alternative medicine: research on users, practitioners and the orthodoxy. Health 1999; 4(2):159-178.

(42) Sirois FM. Treatment seeking and experience with complementary/alternative medicine: a continuum of choice. J Altern Complement Med 2002; 8(2):127-134.

(43) Sirois FM, Gick ML. An investigation of the health beliefs and motivations of complementary medicine clients. Soc Sci Med 2002; 55(6):1025-1037.

(44) Balneaves LG, Bottorff JL, Hislop TG, Herbert C. Levels of commitment: exploring complementary therapy use by women with breast cancer. J Altern Complement Med 2006; 12(5):459-466.

(45) Hirai K, Komura K, Tokoro T, Kuromaru T, Ohshima A, Ito T et al. Psychological and behavioral mechanisms influencing the use of complemetnary and alternative medicine (CAM) in cancer patients. Annals of Oncology 2008; 19:49-55.

(46) Blasche G, Melchart H, Leitner D, Marktl W. Personality does not predict treatment preference, treatment experience does: A study of four complementary pain treatments. Forsch Komplementarmed Klass Naturheilkd 2007; 14:274-280.

(47) Bishop FL, Yardley L, Lewith GT. Treatment appraisals and beliefs predict adherence to complementary therapies: A prospective study using a dynamic extended self-regulation model. British Journal of Health Psychology 2008; 13(4):701-718.

(48) Searle A, Murphy S. Representations of illness: Their relationship with an understanding of and adherence to homoeopathic treatment. Psychol Health 
Med 2000; 5(2):179-191.

(49) Porter M, Kolva E, Ahl R, Diefenbach MA. Changing patterns of CAM use among prostate cancer patients two years after diagnosis: Reasons for maintenance or discontinuation. Complement Ther Med 2008; 16:318-324.

(50) Canales MK, Geller BM. Surviving breast cancer. The role of complementary therapies. Family \& Community Health 2003; 26(1):11-24.

(51) Luff D, Thomas KJ. 'Getting somewhere', feeling cared for: patients' perspectives on complementary therapies in the NHS. Complement Ther Med 2000; 8(4):253259.

(52) Lee-Treweek G. Trust in complementary medicine: the case of cranial osteopathy. The Sociological Review 2002; 50(1):48-68.

(53) Murray J, Shepherd S. Alternative or additional medicine? An exploratory approach in general practice. Soc Sci Med 1993; 37(8):983-988.

(54) Andrews GJ. Placing the consumption of private complementary medicine: everyday geographies of older peoples' use. Health \& Place 2003; 9(4):337-349.

(55) Mercer SW, Reilly D. A qualitative study of patient's views on the consultation at the Glasgow Homoeopathic Hospital, an NHS integrative complementary and orthodox medical care unit. Patient Educ Couns 2004; 53(1):13-18.

(56) Andrews GJ. Private complementary medicine and older people: service use and user empowerment. Ageing Soc 2002; 22:343-368.

(57) Evans MA, Shaw ARG, Sharp DJ, Thompson EA, Falk S, Turton P et al. Men with cancer: is their use of complementary and alternative medicine a response to needs unmet by conventional care? European Journal of Cancer Care 2007; 
16:517-525.

(58) Humpel N, Jones SC. Gaining insight into the what, why and where of complementary and alternative medicine use by cancer patients and survivors. European Journal of Cancer Care 2006; 15:362-368.

(59) Thorne S, Paterson B, Russell C, Schultz A. Complementary/alternative medicine in chronic illness as informed self-care decision making. Int J Nurs Stud 2002; 39(7):671-683.

(60) Patterson C, Arthur H, Noesgaard C, Caldwell P, Vohra J, Francoeur C et al. Exploring adolescent complementary/alternative medicine (CAM) use in Canada. Journal of Interprofessional Care 2008; 22(1):45-55.

(61) Yardley L, Sharples K, Beech S, Lewith G. Developing a dynamic model of treatment perceptions. J Health Psychol 2001; 6(3):269-282.

(62) Balneaves LG, Truant TLO, Kelly M, Verhoef MJ, Davison BJ. Bridging the gap: decision-making processes of women with breast cancer using complementary and alternative medicine (CAM). Support Care Cancer 2007; 15:973-983.

(63) Boon H, Brown JB, Gavin A, Westlake K. Men with Prostate Cancer: Making Decisions about Complementary/Alternative Medicine. Med Decis Making 2003; 23(6):471-479.

(64) Boon H, Brown JB, Gavin A, Kennard MA, Stewart M. Breast cancer survivors' perceptions of complementary/alternative medicine (CAM): Making the decision to use or not to use. Qual Health Res 1999; 9(5):639-653.

(65) Truant T, Bottorff JL. Decision making related to complementary therapies a process of regaining control. Patient Educ Couns 1999; 38:131-142. 
(66) Balneaves LG, Weeks L, Seely D. Patient decision-making about complementary and alternative medicine in cancer management: context and process. Current Oncology 2008; 15(Supplement 2):S94-S100.

(67) Strauss A, Corbin J. Basics of qualitative research. 2 ed. Thousand Oaks: Sage; 1998.

(68) Bishop FL, Yardley L, Lewith GT. Treat or Treatment: A Qualitative Study Conceptualising Patients' Use of Complementary and Alternative Medicine (CAM). Am J Public Health 2008; 98(9):1700-1705.

(69) Paterson C. Measuring outcomes in primary care: a patient generated measure, MYMOP, compared with the SF-36 health survey. BMJ 1996; 312(7037):10161020. 